\title{
A VOZ DAS FAMÍLIAS E AS VOZES SOBRE AS FAMÍLIAS EM UM NÚCLEO DE MEDIDAS SOCIOEDUCATIVAS EM MEIO ABERTO*
}

Sara Regina Munhoz

\section{Introdução}

Em 2012, a Obra Social Dom Bosco Itaquera, na cidade de São Paulo, atendia a cerca de 120 adolescentes autores de práticas infracionais que foram encaminhados pela Vara de Execuções da Infância e da Adolescência (VEIJ) para o cumprimento das medidas socioeducativas em meio aberto (MSE-MA) de Liberdade Assistida (LA) ou Prestação de Serviço à Comunidade (PSC). Desde a promulgação do Estatuto da Criança e do Adolescente (ECA) em 1991, estas medidas tornaram-se práticas privilegiadas de intervenção (Paula 2011; Gregori 2000) por garantirem uma melhor reinserção do adolescente na sociedade e, teoricamente, por serem capazes de romper com a lógica quase causal de inserção do sistema penitenciário e reincidência criminal (Altoé 1993; Villela 2011). Essa legislação propõe que através das medidas em meio aberto os adolescentes apreendidos sejam acompanhados ${ }^{1}$ por uma equipe técnica em atendimentos individuais e coletivos e que, ao mesmo tempo, sejam socialmente promovidos através de encaminhamentos para uma série de serviços públicos (ECA, art. $118^{\circ}$ e art.119º).

Várias pesquisas têm se dedicado a descrever as maneiras como os meninos $^{2}$ e suas famílias compreendem o atendimento das medidas socioeducativas e o processo de ressocialização (Feltran 2011a; Malvasi 2012; Shilittler 2011; Neri 2009, 2011; Paula 2004, 2011). A descrição dos modos como o Judiciário constrói as decisões sobre os casos individuais dos meninos também foi objeto de atenção (Miraglia 2005; Feltran 2011b), assim como trabalhos a respeito dos movimentos que transformaram os "menores infratores" em "pessoas em desenvolvimento" detentoras de uma série de direitos (Nogueira de Lima 2010; Paula 2011; Vargas \& Marinho 2008; Rizzini 2002, 2009; Volpi 2011). 
Minha contribuição para esse debate parte de outro problema: como as pessoas encarregadas de lidar com a gestão dessa população específica construíam os seus argumentos, direcionavam suas ações, interpretavam seus trabalhos cotidianos. Descrevo as tarefas dos técnicos na construção dos atendimentos que são requeridos pelo Poder Judiciário a partir de uma imagem acionada corriqueiramente pela equipe: os técnicos consideravam-se pontes entre os meninos e suas famílias, de um lado, e o Poder Judiciário, de outro. Argumento que é possível estender essa imagem (Wagner 2010:79) para compreender a relação construída cotidianamente entre duas lógicas distintas: a das variações de cada atendimento, com seus enunciados específicos, de um lado, e a da rigidez dos documentos que produziam, de outro. Proponho analisar enunciados e documentos sem almejar recompô-los em qualquer totalidade orgânica (Haraway 2009:40). O esforço dos técnicos, assim como o meu esforço neste texto, era o de articular parcialidades: fazer ver e obliterar saberes que, embora demandados pelo Poder Judiciário, só podem ser construídos no núcleo. A eficácia dos documentos, possibilitada pelo controle da escrita técnica, não apagava uma série de tensões e saberes que se davam em outros campos e em outros tempos. O trabalho da equipe se construía a partir de traduções e analogias, mas, para que elas se tornassem possíveis, saberes que não seriam vistos pelos juízes precisavam ser colecionados no núcleo.

A equipe da Dom Bosco, composta por oito profissionais, dividia-se nos atendimentos aos meninos e os acompanhava ao longo dos meses estipulados pelo juiz para o cumprimento da medida. Esses profissionais eram responsáveis por sensibilizar os adolescentes sobre os riscos do mundo infracional; precisavam ainda orientar os meninos sobre as exigências implicadas em um atendimento socioeducativo; deveriam, enfim, encaminhá-los a serviços públicos, principalmente relacionados às áreas de educação, saúde e profissionalização (Paula 2011). Simultaneamente, eram encarregados de repertoriar o núcleo e os juízes com seus Registros de Atendimento, Relatórios técnicos, Instrumentais e toda uma série de outros documentos. Para que a equipe técnica pudesse realizar a dupla tarefa, as famílias dos adolescentes também precisavam ser escrutinadas e acompanhadas pela equipe. ${ }^{3}$ Elas eram convocadas a falar de si e dos seus, e eram inscritas em cada um dos documentos produzidos sobre os adolescentes.

No serviço de MSE-MA Dom Bosco a presença das famílias era constante, ainda que, muitas vezes, incorpórea. Elas estavam nos cartazes que recepcionavam visitantes e frequentadores do núcleo; nos documentos que circulavam entre salas, prédios, ônibus e metrôs: de mão em mão, de pasta em pasta; nas falas dos técnicos que acionavam, por telefonemas ou docu- 
mentos, sua presença; nos discursos que eram emitidos oral ou graficamente para as instituições exteriores ao núcleo. Neste artigo, discuto a forma como o protagonismo familiar era construído a partir de um duplo movimento, que envolvia um deslocamento enunciativo: o protagonismo das famílias nos atendimentos demandava sua presença nas reuniões e nos encontros individuais na mesma medida em que nos documentos elaborados pela equipe e enviados ao Poder Judiciário. Na circulação pelo corredor onde funcionavam as medidas socioeducativas, em cada uma de suas salas, saberes específicos eram produzidos a respeito das famílias e dos meninos atendidos.

Na primeira parte do artigo apresento o conjunto de materiais que explicita um dos momentos em que a voz das famílias, que se devia fazer ouvir, não demandava registro. São as Terapias Comunitárias, lugar em que as intimidades eram obrigatoriamente ditas, embora não fossem descritas. As histórias privadas de cada família, os detalhes de sua organização, os sentimentos que as atravessavam encontravam um espaço de possível esmiuçamento. Nos espaços das intimidades escancaradas, a voz da família que se dizia em primeira pessoa se transformava em declarações de comparecimento, carimbos, listas de presença e relatórios - estes sim com visibilidade e eficácia judiciais, como demonstra a segunda parte do texto. A partir de vários documentos acessados em campo, apresento os momentos em que outra família emergia: aquela descrita de maneira analítica; a que precisava ser apontada, exposta e interpretada tecnicamente. Aqui é a família em terceira pessoa que se fazia presente, quase ao mesmo tempo em que a família que se diz é diluída. O artigo se constrói, portanto, pendulando entre essas diluições e condensações concomitantes, e entre os diferentes alcances que cada um desses desenhos familiares encontrava nas MSE-MA.

\section{Família que se diz}

Embora este artigo se baseie na divisão entre dois tipos de enunciados produzidos em espaços diferentes e com efeitos distintos no andamento dos atendimentos, é importante ressaltar de saída que essa divisão é analítica e, portanto, artificial. Uma estratégia descritiva que visa, através da própria separação e do contraste, afirmar a indissociabilidade de falas e documentos. Muito rapidamente se percebe que a exigência de que as famílias falassem e o registro desses enunciados eram interdependentes e quase concomitantes. Eles se retroalimentavam. Descrever a transubstanciação das falas em documentos implica a necessidade de, em alguma medida, mostrar a todo momento os pontos permanentes de contato entre os discursos que se 
A VOZ DAS FAMÍLIAS E AS VOZES SOBRE AS FAMÍLIAS EM UM NÚCLEO DE MEDIDAS SOCIOEDUCATIVAS EM MEIO ABERTO

davam em primeira pessoa e aqueles que se construíam em terceira pessoa. O trabalho da equipe, como ponte que era, exigia um controle dos conteúdos e das formas de explicitação desses diferentes materiais (Riles 2001; Reed 2006; Hull 2012; Lewandowski 2014; Morawska Vianna 2014). Nessa primeira parte, portanto, descrevo como as famílias eram conduzidas aos atendimentos e, principalmente, às Terapias Comunitárias. E, ainda, como essa condução se dava por estratégias persuasivas apoiadas, de modo geral, em justificativas documentais.

Em consonância com as propostas do ECA (Gregori 2000:165), o cumprimento de MSE-MA pressupõe que uma rede de instituições e apoios se articule ao redor dos adolescentes: suas inserções em uma série de serviços públicos é um dos efeitos desejáveis dos atendimentos e funcionam, elas mesmas, como índices de ressocialização. ${ }^{4}$ Estes, por sua vez, só podem ser evidenciados através da escrita técnica. Mas para que esses saberes e apoios institucionais se concretizassem e a equipe compilasse elementos necessários para alimentar seus documentos, as famílias dos adolescentes autores de práticas infracionais precisavam ser incessantemente convocadas a participar do cotidiano dos atendimentos.

Quando o juiz decidia que a medida em meio aberto deveria ser imposta ao adolescente autor de prática infracional, encaminhava-o a um dos núcleos encarregados pelos atendimentos. A descrição da medida podia ser muito genérica, determinando apenas o tipo escolhido (LA e/ou PSC) e o prazo para seu cumprimento. Mas o juiz podia optar por enumerar que índices exigiriam aprovação ao término do processo. Nesses casos, era frequente que elencasse, além das atividades e dos encaminhamentos que deveriam ser cumpridos pelo adolescente, as "medidas protetivas cumuladas" que precisariam ser observadas (Munhoz 2015). Nessa categoria se enquadravam as participações das famílias nos "grupos de apoio familiar".

A explicitação desse encaminhamento no Termo de Entrega não era imprescindível. ${ }^{5}$ Mesmo em documentos menos pormenorizados, os técnicos se esforçavam por sensibilizar as famílias a participar das atividades promovidas pelo núcleo e empenhavam-se ainda em transformar essa participação em registros eficazes no momento das decisões judiciais que pudessem dar por encerradas as medidas. Um dos signos que deixam clara a centralidade das famílias na construção dos atendimentos é, portanto, a exigência mais ou menos evidente de que, juntamente com os meninos, seus responsáveis explicitassem suas relações e estruturas familiares, evidenciassem sua participação, rememorassem seus avanços. Precisavam, também eles, cumprir a medida, como bem notavam muitas mães que frequentavam as atividades promovidas pelo núcleo: 
Eu posso falar, não tenho vergonha não, porque eu acho que está todo mundo na mesma situação, não é? Eu tenho meu filho de 19 e esse de 15, mas já tinha chegado a um ponto que eu já tinha abandonado [...] Porque pode falar o que for, mas a gente paga junto. Paga até mais. Eu falava: "não fiz nada! Por que tenho que pagar? Tenho que ficar indo lá?". A gente trabalha, tem que ficar fora de casa. Aí tem que perder dia, fazer um monte de coisas por causa das coisas erradas que eles fazem?

Como contestava essa mãe, a presença das famílias no núcleo se dava por uma série de imposições e implicavam outros tantos sacrifícios: os responsáveis perdiam dias de trabalho, deixavam seus afazeres, deslocavam-se até o núcleo, precisavam apresentar atestados em seus empregos que denunciavam a situação de seus filhos. De modo semelhante àquele descrito por Ferraz de Lima (2015:88), as mães das medidas pareciam interpretar o sentido de família conferido pela instituição a partir das noções "ter-família" e "ser-família". Entendiam a qualidade positiva que suas presenças no núcleo representariam ao atendimento de seus filhos: "ter família era sinônimo de agente de ressocialização". Ao mesmo tempo, "ser-família" de meninos das medidas não deixava de conferir ao próprio sentido de família um significado negativo, com uma série de consequências. Era comum que entendessem as exigências - repetidamente apresentadas pela equipe técnica como oportunidades e direitos - como uma pena, um fardo. "Não é a gente que precisa vir, são eles!", dizia um pai em uma das Terapias Comunitárias. Mas mesmo sem terem cometido os atos infracionais, os responsáveis pelos adolescentes eram também responsáveis pelas possibilidades de sucesso dos atendimentos.

Os técnicos reconheciam os limites de participação que cada caso proporcionaria. Através do manuseio de documentos e a partir dos atendimentos que promoviam, eram capazes de diagnosticar com relativa precisão os casos em que poderiam contar com o respaldo familiar e com a adesão dos adolescentes. Naqueles atendimentos em que diagnosticavam a possibilidade de participação familiar, o esforço se voltava às tentativas persuasivas de trazê-las às reuniões propostas pelo núcleo, que podiam ser individuais ou coletivas. Também acionavam as famílias por telefonemas e encontravam-se com elas nas visitas técnicas realizadas.

Veremos adiante como se construíam, já no primeiro encontro, documentos essenciais para o desenrolar dos atendimentos. Para que essa entrevista inicial se transformasse em papéis, uma série de ponderações precisava ser observada. Histórias familiares rememoradas, narrativas das trajetórias dos adolescentes, relacionamentos dos pais, condições socioeconômicas dos membros da família, possíveis envolvimentos de outros 
familiares com o meio infracional eram todos ouvidos e transformados em registro. Um registro técnico, tabular e, no limite, estatístico. Depois desse primeiro encontro, as famílias continuavam falando de si nos atendimentos individuais a que eram convocadas, e nas visitas técnicas ou telefonemas que trocavam com os responsáveis pelos atendimentos. Esses enunciados das famílias sobre si mesmas eram muito raramente transcritos em primeira pessoa, embora registros sintéticos dos encontros fossem cuidadosamente compilados nas pastas de cada um dos adolescentes. Na passagem do que diziam ao que demandava registro, muito se transformava, formas se eliciavam (Strathern 1991).

Explicar aos meninos e às famílias que o cumprimento da MSE-MA supera a premissa da presença semanal no núcleo era uma tarefa corriqueira. Era preciso orientá-los sobre a demanda de uma produção enunciativa constante. Era preciso que entendessem a medida como um espaço em que os direitos se colocavam de maneira impositiva e que requeria dos adolescentes e familiares a coleção de ações capazes de, mesmo sem garantias prévias, persuadir o juiz a encerrar o atendimento depois do tempo mínimo estipulado.

Em uma das tardes de trabalho de campo, um adolescente se apresentou com seu pai e sua advogada, situação pouco comum na MSE-MA. Ele havia recebido uma Intimação de Comparecimento ao núcleo, depois de ter se ausentado durante algumas semanas, e a técnica enfatizava que ele tinha "dado sorte" de o juiz não ter expedido um Mandado de Busca e Apreensão, que lhe custaria mais 90 dias de internação na Fundação CASA. Ele estava bastante inquieto e insistia: "só faltava eu apresentar os documentos, senhora. Já vou encerrar, já". A equipe precisou se empenhar para esclarecer ao adolescente e ao seu pai que o encerramento da medida dependia de uma decisão judicial que não se encaixava em uma lógica certeira e causal, mas que envolveria, seguramente, uma averiguação do acompanhamento da família na medida dos avanços que precisariam ser demonstrados pelo próprio adolescente (através, principalmente, de atestados e protocolos).

A equipe acreditava ser pouco provável que o juiz acatasse a sugestão de encerramento sem que a família do adolescente, preferencialmente sua mãe, participasse dos "grupos de orientação e apoio", comumente chamados de Terapias Comunitárias. Para os técnicos, este seria o índice de acompanhamento cobrado neste caso específico. "É uma determinação do juiz", destacavam. O adolescente se recusava a participar dos encaminhamentos, e a equipe precisou enfatizar o fato de que a exigência não decaía sobre ele: "É para a família, J! ${ }^{6}$ Pra sua mãe. Se ela não vier, o juiz não encerra". Diante das acusações do pai, que a responsabilizava pelo envolvimento de seu filho com o mundo infracional, a coordenadora da equipe explicitava a importância das famílias para o bom andamento das MSE-MA: 
É, mas o senhor não acompanhou, acompanhou? [...] porque o problema é que a família só aparece aqui quando vem intimação do juiz. Aí vem tanta gente que nem cabe na sala. E todo mundo diz que tá junto, que acompanha. Mas durante a medida mesmo, todo mundo some.

Ainda que o adolescente se comprometesse a frequentar o núcleo, a retomar seus estudos, a procurar se profissionalizar e ser inserido no mercado de trabalho, ainda que, desse modo, demonstrasse todos os avanços que pudesse supor serem estimados pelo juiz, as chances do encerramento da medida seriam diminutas sem o acompanhamento da sua família - este comprovado pela sua presença, principalmente, nas Terapias Comunitárias.

A ausência das famílias, tão combatida pela equipe, impedia que os técnicos alimentassem satisfatoriamente seus registros com as informações que seriam avaliadas pelos juízes no momento do encerramento da medida, como veremos adiante. Não era possível que a equipe preenchesse as lacunas, elaborasse seus registros sem a presença das famílias no núcleo. Essa presença, mais do que especificamente seus enunciados, era o material indispensável para a alimentação dos registros técnicos. Poder inseri-las nos documentos e evidenciar a sua presença implicava, necessariamente, a transubstanciação entre aquilo que os técnicos ouviam e o que era preciso escrever.

As Terapias Comunitárias, oferecidas mensalmente pela Dom Bosco, eram o principal espaço de participação das famílias desacompanhadas dos adolescentes atendidos. Os encontros eram conduzidos por duas psicólogas da equipe que ali se colocavam como simples mediadoras das reuniões. Nos documentos vindos do Judiciário ou das unidades da Fundação CASA, e nos próprios relatórios de fechamento mensal elaborados pelo núcleo, as Terapias eram chamadas de Grupos de Apoio à Família. A exigência da participação das famílias nesses grupos muitas vezes já se dava antes mesmo de o adolescente ser atendido em meio aberto. Muitas mães que frequentavam a Terapia Comunitária na Dom Bosco chegavam ao núcleo por encaminhamentos da Fundação CASA, onde seus filhos permaneciam internados. Ao final de cada reunião, elas recebiam declarações de comparecimento, que deveriam ser entregues nessas unidades.

As técnicas orientavam os participantes a não oferecerem conselhos e costumavam dizer que "o que funciona bem para uma pode não funcionar para as outras, mas a troca de experiências pode ajudar todas". Convidavam os presentes a contarem seus sofrimentos e suas conquistas, principalmente os que envolviam os meninos das medidas. ${ }^{7}$ Nas reuniões, as técnicas defendiam a Terapia como uma atividade que auxiliava as mães, através da troca de experiências, a buscarem "recursos internos" para lidar com a situação em que seus filhos se encontravam. ${ }^{8}$ Para isso, elas eram convidadas a expor no 
grupo detalhes de suas organizações familiares, de seus trabalhos, e do tipo de relação que mantinham com seus filhos. O objetivo, enfatizado com frequência, não era "impor verdades", mas compartilhar experiências de modo que todos pudessem se beneficiar.

As lágrimas, a coragem, a força das mães eram sublinhadas em todos os encontros. As pequenas vitórias, as discretas mudanças, os menores avanços eram sempre comemorados: lutas contra o vício das drogas ilícitas, matrículas escolares, um novo emprego, as novas amizades. A culpa era combatida quase na mesma medida em que o apoio e o respaldo das mulheres às suas famílias eram incentivados. Essas mulheres encontravam no espaço da Terapia Comunitária discursos que valorizavam sua importância na organização das famílias - e, consequentemente, na ressocialização dos seus filhos - e que procuravam, ao mesmo tempo, garantir um fortalecimento individual que as desvinculasse do papel integral e permanente de mães. Ainda que a participação fosse obrigatória em alguns casos, a estratégia persuasiva da equipe era ressaltar as vantagens de suas presenças no núcleo não para o desenvolvimento dos atendimentos, mas para suas próprias vidas, como enfatizava uma das técnicas em um dos encontros:

Não adianta, por mais difícil que seja, pensar que a culpa é toda de vocês. Porque é como eu sempre falo, mas é verdade. Cada um é diferente do outro. A gente educa seis, oito filhos tudo igual, né? Mas cada um tem um jeito. E os motivos que levam pra isso são muitos. Por isso a F tá certa quando diz que vocês têm que se cuidar.

Em todos os encontros que acompanhei foi reforçada ideia de que a presença das famílias nas reuniões era um direito, ainda que obrigatório e inalienável. Uma oportunidade que as ajudava a se fortalecerem, a se livrarem das culpas, a buscarem os recursos para lidar melhor com as situações. Nesse processo de fortalecimento individual, histórias sobre membros das famílias que sequer estavam cumprindo as medidas costumavam ser trazidas à tona. Trajetórias de longos anos que costumavam apresentar padrões que se repetiam, lutas que não se encerravam nos meses da medida, eram expostas nas Terapias:

O meu [filho] tem 36 [anos] e é assim. Eu acho que ele tá melhor, ele diz que tá melhor, mas depois volta tudo como antes. Faz 21 anos que eu tô nessa vida com ele. E eu te falo uma coisa: eu não desisto do meu filho! Eu amo muito ele! Sofri muito nessa vida. Não tinha muito dinheiro, tive síndrome de pânico, nem conseguia cuidar deles. Sou muito ansiosa, sabe? O menor, que tá aqui agora assinando, tinha oito meses. O primeiro e o último! É difícil, a gente sofre muito, tem muita dor, mas eu não desisto. Porque Deus tem um plano para ele! 
Constantemente as mães recapitulavam acontecimentos que extrapolavam o ato infracional que levara seus filhos àquelas intervenções. Outros filhos, maridos, patrões, vizinhos eram mencionados, permitindo que todos os presentes destrinchassem relações que superavam vastamente os motivos pontuais que as arrastaram até ali. "Fortalecer os vínculos familiares" e "angariar recursos internos", objetivos das Terapias descritos nos documentos, passava necessariamente pelo ouvir e pelo falar de si e dos seus, justificando-se, perseguindo os motivos, chorando os sofrimentos e evidenciando sua força. Elas mesmas interpretavam o seu protagonismo no processo que as havia arrastado, junto com seus filhos, ao núcleo, e se questionavam sobre o que poderia, no limite, ter sido a causa de suas próprias inserções em uma rede institucional tão complexa:

Eu não sei se é porque tive filho muito nova, né? E um atrás do outro. Eu tive oito filhos. Mas eu fiz o que podia. Tem três que já tão casadas, a de 22, a de 20 e a de 18. Já tenho até netos. Eu tentei dar educação. Olhava os cadernos deles, se tinha reclamação da professora, já resolvia, comprava o material. Mas a gente tem oito e quer que todos fiquem bem.

Na construção dessas narrativas, as famílias elaboravam constantemente reflexões morais a respeito das organizações familiares e avaliavam a relação entre esses modelos e a inserção dos adolescentes no mundo infracional.

Eu considero que minha família é estruturada. Eu e o pai dele somos casados há 18 anos. O pai dele nunca bebeu, nem fumou, é trabalhador. Eu também. Só teve bom exemplo em casa. E não é como esses meninos, sabe? Tem uns que precisam disso. Ele não precisava. A gente sempre deu o que ele precisava, sempre deu escola e o que ele pedia. Eu ainda não acredito, sabe?

Concomitantemente, a equipe esforçava-se por recrutar a participação familiar também apoiada em uma percepção - justificada por suas interpretações da legislação e por sua experiência de relacionamento com o Poder Judiciário - das famílias como fundamentais para o sucesso do processo socioeducativo. Barbosa, Cruz e Vidal (2012) argumentam que o destaque que as famílias têm dentro das políticas de assistência seria uma forma de reconhecimento de sua "influência na formação e no comportamento de seus membros". Para elas, o êxito das MSE-MA depende

do empoderamento das famílias quanto à sua importância, seus direitos e seus papéis. [...] Segundo o Sinase, as práticas sociais devem, através de atividades programáticas, visar à participação qualitativa da família no processo socioeducativo, a fim de propiciar o fortalecimento de vínculos e a inclusão dos adolescentes no ambiente familiar e comunitário (2012:195). 
O empenho constante da equipe em ressaltar a importância do acompanhamento e da participação das famílias se dava ao mesmo tempo em que qualquer desvio do modelo ideal pudesse ser acionado como o motivo da inserção dos adolescentes no mundo infracional e das dificuldades de condução do processo ressocializador. Os responsáveis podiam ser identificados como os que não se posicionavam como "figura de autoridade", os que "não acreditavam" na melhora de seus filhos, os que não tinham "uma rotina estruturada", os que se abstinham demais pelas "necessidades do trabalho", os que se encontravam "fragilizados", os que estavam "nas mãos" dos meninos, como os que "seguem a vida". Uma série de juízos era sempre acionada pelos técnicos da equipe na ponte que faziam entre as famílias e o Poder Judiciário, para que a organização familiar fosse suficientemente alocada em cada processo socioeducativo. Liana de Paula (2011) destaca que nas medidas socioeducativas há um "novo modelo" a partir do qual a realidade familiar dos adolescentes atendidos é "observada, medida, comparada e, também, ajustada". Esse modelo

define-se pela idealização das relações familiares, entendidas como afetivas, estabelecendo obrigações recíprocas e mútuas de sustento, guarda e educação das crianças e adolescentes [...] [O] novo modelo implica o estabelecimento de padrões ideais de afetividade, cuidado e educação que serão medidas e sobre os quais a intervenção será organizada (2011:171).

Ressalta que é a partir das intervenções que se visa, nas MSE-MA, aproximar a família dos meninos de padrões que são "relacionais e não estruturais", ajustando suas relações afetivas "disfuncionais". Argumento, com mais ênfase na seção que se seguirá, que embora essas exigências de participação familiar sejam legais e judicialmente requisitadas, os índices de relações afetivas e de cuidado e os diagnósticos sobre o cumprimento das obrigações familiares se constroem a partir de gaps (Strathern 1991) entre os saberes que se colecionam no núcleo e as formas como eles são evidenciados em uma outra escala.

Não obstante as intimidades muitas vezes fossem escancaradas nesses encontros e que as mães trouxessem à tona informações que ultrapassavam o ato infracional cometido por seus filhos, o que elas diziam raramente ficava registrado nas pastas dos meninos, mesmo quando as técnicas que os atendiam individualmente eram as responsáveis pela Terapia. De qualquer modo, tratava-se de um espaço em que a exposição da organização familiar e dos sentimentos que atravessam essas relações eram condição ou exigência da medida. No limite, ainda que as mães decidissem por uma presença marcada pelo silêncio, estavam expostas às realidades de outras mães, às histórias 
de outros meninos que, como os seus, envolveram-se em atos infracionais. A medida socioeducativa exigia que os adolescentes e suas famílias recobrissem "a memória toda de sua vida nos mínimos atos e acontecimentos, expondo-a, examinando-a por todos os lados" (Kafka 2005:128).

Para os técnicos, cada um desses espaços de "fortalecimento dos vínculos familiares" era eficaz na "busca de recursos internos" para que as mães lidassem adequadamente com os complexos dilemas que precisavam enfrentar. Em contrapartida, e simultaneamente, não ignoravam o caráter estatal ou jurídico dos encontros.

Estavam certos de que a eficácia das reuniões era garantida pela soma de ao menos dois fatores: a troca enriquecedora de experiências e a assinatura nas declarações de presença que cada uma daquelas mães deve receber. Sabiam também que, aos olhos do juiz, o peso dessa assinatura obliterava todos os diálogos, todas as exposições, toda a abertura que fora de alguma maneira exigida. Ainda que o juiz não tivesse acesso ao que foi dito, a ciência de que a família do adolescente havia sido participativa - características sinalizadas de uma maneira especial nesses encontros - garantiria o entendimento de que o adolescente pôde contar com o respaldo familiar tão frequentemente exigido nas medidas. "O juiz não libera se não tiver respaldo familiar", disse-me uma das secretárias. Respaldo que, em outra escala, só se comprova se estiver declarado, assinado e carimbado.

Do outro lado da ponte, o comprometimento das famílias e o "fortalecimento dos vínculos" apareciam como decisivos para o sucesso nos pedidos de encerramento das medidas (Sinase, art. $35^{\circ}$, inciso IX).$^{9}$ Como argumenta Vianna (2005) ao tratar de relatórios sociais em processos jurídicos, as moralidades só podem ser apreendidas se forem descritas, e transformam-se em indicativos da inscrição das famílias em uma ordem de obrigações. No caso das MSE-MA Dom Bosco Itaquera, os sentimentos expostos nas Terapias precisavam transformar-se em registros técnicos muito abreviados. A próxima seção se debruçará sobre a passagem para o modo como os vínculos e o respaldo familiares se protagonizavam nos papéis.

\section{Família que é descrita}

Em outro nível - a partir de documentos - continuarei expondo nesta seção a centralidade das famílias na construção dos atendimentos. Quando o que acontece no núcleo ganha registro, diferentes formas de ver e de ser família se evidenciam. A família passa a ser protagonizada para outros atores, em outros lugares. Para explicitar esse deslizamento, utilizo, eu mesma, uma 
mudança de escala em meus materiais. A primeira seção se compôs a partir de minhas próprias impressões em campo e se amparou em imagens que eu julguei apropriadas para nos fazer ver as famílias que, naquele espaço, se diziam: famílias eloquentes, que falavam de si, que falavam dos seus, que precisavam falar. Famílias que narravam seus sofrimentos, suas culpas, suas lutas. Esta segunda seção, por sua vez, se construirá a partir de imagens e analogias que os técnicos lançam mão em sua escrita. Essa possibilidade de movimentação descritiva foi orientada pela minha circulação pelo corredor das medidas, assim como pela circulação dos papéis. Na mesa dos técnicos ou na secretaria do núcleo, pude ler e transcrever uma série de documentos de adolescentes atendidos pela Dom Bosco. Lidar com esses papéis e acompanhar as discussões, o cuidado e o tempo despendido na construção e na interpretação dos registros revelaram a centralidade de sua circulação e a importância do controle da escrita nas tentativas de persuasão dos juízes responsáveis por cada caso.

Os documentos, como argumentam Ferreira (2013), Santos (2014) e Costa (2015), são artefatos que dão movimento aos processos e, ao serem lidos, produzem efeitos de realidade. Nas MSE-MA, o cuidado com sua elaboração está ligado à consciência que os técnicos tinham desses efeitos nas vidas dos meninos e de suas famílias. Escrever relatórios "bem fundamentados" era crucial para que os efeitos jurídicos atravessassem as vidas dos atendidos (Munhoz 2013b). A escrita transformava, por extensões e lacunas, as vozes das famílias em declarações e descrições breves e precisas apresentadas em relatórios que comprovavam sua presença no núcleo. Ocorria um deslocamento enunciativo: a família que falava de si era agora evocada em terceira pessoa, em orações diagnósticas que realçavam os índices do processo ressocializador que, do ponto de vista dos técnicos, seriam valorizados pelos juízes responsáveis por cada um dos casos (cf. Vianna 2002:276). Considerando-se pontes, os funcionários transformavam o que ouviam em textos que pudessem ser lidos eficazmente em outra escala, produzindo - ao menos potencialmente - os resultados que julgavam adequados em cada caso particular.

Com Strathern (1991:97), argumento que o eclipsamento operado pelos técnicos de certos saberes recolhidos no núcleo funcionava, ele mesmo, como parte de um novo conhecimento que precisava ser construído em uma escala distinta a partir de outro vocabulário e de outros materiais. Para isso considero, com Mol (2002:153), que o conhecimento - aqui, os documentos produzidos pela equipe - não deve ser tratado primariamente como referencial, como um conjunto de afirmações sobre uma realidade prévia, mas como uma prática que interfere em outras práticas. Isto significa que, ao 
invés de procurar objetos que estariam dados de antemão, almejo observar as práticas que os colocam em contato. Desse modo, não argumento que os documentos são falhos por produzirem seus "gaps", mas que, juntamente com todos os outros saberes que atravessam as medidas, são responsáveis por produzir famílias. ${ }^{10}$

O Relatório Inicial era o primeiro parecer sobre a situação do adolescente e de sua família enviado do Poder Judiciário. Era o mais urgente, descritivo e completo, ainda assim dificilmente superava as duas páginas. Nele se apresentavam as possibilidades (sempre otimistas, mas realistas) de desenvolvimento da medida. Ali também se desenhavam as metas e as ações ${ }^{11}$ individualizantes de cada um dos casos. Semanalmente, ao menos um dia completo de trabalho da equipe era dedicado à escrita desses relatórios. O casamento dos pais, onde eles viviam, quantos filhos tinham e a renda familiar eram elementos de corriqueiro registro nesses documentos. Indicavam-se as orientações e os encaminhamentos já oferecidos no primeiro atendimento. No relatório de $\mathrm{D}$, os técnicos limitaram-se a registrar que o "responsável foi convidado e orientado a participar dos grupos de apoio e orientação familiar promovidos por este núcleo, os quais têm como objetivo o fortalecimento intrafamiliar".

No entanto, era comum que se descrevessem as impressões iniciais coletadas no primeiro atendimento. Os técnicos lidavam com presteza com termos e expressões muito específicos para já no início do atendimento sinalizar as possibilidades de sucesso que a medida prenunciava e os limites que poderia enfrentar. O relatório de $\mathrm{P}$, por exemplo, registrava que a "senhora [nome da mãe] relata que sempre teve problemas com o comportamento de P", e "ressalta que o tirou da escola e posteriormente o levou para a casa do pai, pois não possuía mais o controle da situação". P era usuário de crack e cocaína desde os 9 anos, fato também brevemente descrito. Propuseram-se, nesse atendimento, encontros individuais, semanais e visitas a P. Registrou-se também que a mãe fora "convidada a participar de nossas reuniões quinzenais, que visam ao fortalecimento intrafamiliar". O técnico responsável por esse adolescente concluiu o relatório enfatizando a "postura impaciente" de P durante a acolhida e a "fragilidade" da mãe "perante a situação". O cuidado na escrita dessas impressões dialoga com o argumento de Ferreira (2013:60) de que registros deste tipo ensejam "compromissos, sentimentos e obrigações" em relação às famílias e delegam responsabilidades "cuja efetividade deriva em larga medida da força social desses papéis".

Em 2012, respondendo a algumas exigências de mudanças burocráticas na construção dos atendimentos, os técnicos formularam um modelo de Relatórios Inicial que recorria diretamente ao Sinase e aos seus objetivos, 
vinculando-o explicitamente às atividades propostas no núcleo. Nesse novo modelo de relatório, os objetivos da medida socioeducativa eram pontuados

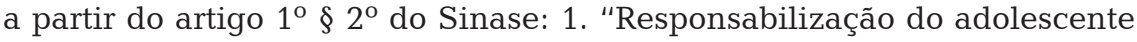
quanto às consequências lesivas do ato infracional"; 2 . "A integração social do adolescente e a garantia de seus direitos individuais e sociais"; 3. "Desaprovação da conduta infracional". Encaminhamentos e orientações promovidas nos atendimentos semanais eram elencados como ações relacionadas aos segundo e terceiro objetivos. Para que o primeiro objetivo fosse atingido, sugeria-se explicitamente como ação, além do "atendimento individual e grupal" do adolescente, a

Participação da responsável nos grupos de apoio e orientação familiar e Terapia Comunitária: quanto aos grupos familiares, a genitora [...] e também o genitor [...] se dispuseram a participar da Terapia Comunitária. Orientamos que o próximo encontro será no dia [...] às [...]h, e terá como objetivo propiciar um momento de reflexão e discussão de temas referentes ao relacionamento familiar, responsabilização do adolescente, dentre outros temas que envolvem a medida socioeducativa.

Reservava-se ainda, abaixo das ações ligadas aos três objetivos exigidos pelo Sinase, uma seção específica sobre a Situação familiar, em que se sinalizava:

Segundo informações colhidas em entrevista inicial, o jovem reside com a genitora $\mathrm{Sr}^{\mathrm{a}} \mathrm{M}$. que é funcionária pública e percebe $\mathrm{R} \$ 3.000,00$ mensais; mora também com os irmãos: M. (23), M. (19) e a avó materna Sr. ${ }^{a}$ G. (81). Residem em casa própria com 05 cômodos e infraestrutura local. A genitora também nos informou que recebe pensão do pai de $\mathrm{M}$. no valor de $\mathrm{R} \$ 600,00$.

E, finalmente, o modelo se encerrava com o Parecer/ Avaliação do Orientador/ Técnico, seção sempre presente nos relatórios anteriormente escritos pela equipe, mas que teve sua importância reforçada a partir de um modelo que propunha descrições um pouco mais detalhadas:

M. compareceu acompanhado da genitora $\mathrm{Sr}^{\mathrm{a}}$ M. em 17.01.13 para dar início à medida, e no dia 22.01.13 compareceu acompanhado do genitor Sr. S. para atendimento. O genitor reside na zona norte da cidade, mas relatou que está disposto a acompanhar a medida socioeducativa e participar dos grupos de família conforme agendados. Disse também que procurou respaldá-lo durante a internação e admitiu que o ocorrido, provocou mudanças em sua forma de pensar, pois diferentemente de julgá-lo de forma rígida e autoritária, atualmente acredita que o acompanhamento familiar é necessário para que o adolescente possa se desenvolver de maneira saudável e passar por esta difícil situação. 
Percebemos que M. se relaciona de forma respeitosa com os genitores e ambos demonstram interesse quanto aos encaminhamentos realizados durante os primeiros atendimentos: documentação e profissionalização.

O modelo de Parecer acionava alguns dos índices que os técnicos julgavam ser valorizados pelos juízes como índices de um atendimento eficiente, como um genitor "disposto a acompanhar a medida", que respalda o adolescente e se dispõe a participar das reuniões promovidas no núcleo. Como documento a ser consultado no momento de escrita dos relatórios, ele evidenciava de modo muito explícito a importância de protagonizar a família sempre que possível nos papéis que circulavam entre o núcleo e o Poder Judiciário.

Além desses relatórios cuidadosamente construídos logo de saída para persuadirem os juízes dos limites e dos alcances de cada atendimento, a equipe também elaborava os Planos Individuais de Atendimento (PIAs) e os Relatórios de Acompanhamento, que tendiam a ser bastante abreviados. Palavras-chave muito específicas precisavam ser acionadas para dar conta, com pouca tinta, da imagem dos atendidos que os técnicos almejavam construir. Esforçavam-se por construir um registro do tolerável e do possível em cada um dos casos (Vianna 2002:294). Mas era preciso, invariavelmente, que em sua escrita fossem capazes de fabricar a presença das famílias aos olhos do juiz.

Os PIAs eram escritos pari passu com os Relatórios Iniciais. Os primeiros já começam a ser produzidos imediatamente depois na Reunião de Acolhimento, no primeiro atendimento individual. Esse encontro também era registrado nos Instrumentais produzidos pela equipe (onde é chamado de Grupo de Família "Acolhimento") e anexado nas pastas dos adolescentes. Os técnicos declaravam nesse registro descrições como

Frisamos sobre a importância da participação dos pais no cumprimento da medida, pontuando sobre os grupos familiares de apoio e orientação, assim como a Terapia Familiar, e também sobre os serviços oferecidos pela rede que nos auxilia no atendimento.

Em seguida, frente a frente com cada família, preenchiam os documentos individuais que serviriam, por um lado, para a obtenção de dados estatísticos e, por outro, para a elaboração descritiva mais detalhada do Relatório Inicial que deveria ser enviado com certa urgência ao juiz encarregado do caso.

Os Planos Individuais de Atendimento eram formulários compostos por 13 campos a serem descritos (Munhoz 2013b). A família estava presente 
em praticamente todo o documento. Ali se registrava se o adolescente tinha esposa/companheira e/ou filhos; qual era o estado civil de seus pais; quem seria responsável por ele durante a medida; como seriam os atendimentos familiares (individuais ou em grupo, semanais ou quinzenais); quais eram os nomes, o parentesco, a idade, a escolaridade, a formação profissional, a ocupação e o salário mensal de cada uma das pessoas que residiam na mesma casa que o atendido e, finalmente, se alguém de sua família tinha histórico infracional e/ou penitenciário. Somada a todas essas informações coletadas e registradas, uma das seis áreas de atuação da medida elencada no Contrato de Compromisso era exclusivamente voltada para a família. ${ }^{12}$ Neste espaço, metas e ações propostas precisavam ser descritas e um prazo para seu cumprimento deveria ser estipulado.

Embora houvesse variações nos modos como cada técnico preenchia o Contrato de Compromisso, com base nos vários PIAs consultados em campo, é possível afirmar que a principal proposta feita às famílias ao longo do atendimento inicial era apresentada nestes documentos pelo termo sensibilização. De acordo com os documentos, as famílias eram nessa primeira reunião sensibilizadas a participar dos "grupos de orientação e apoio" através de "orientações, convocações da família e visitas domiciliares". Havia Planos em que a meta descrita pelo técnico era "convidar: solicitar a participação dos familiares nas reuniões" para que se verificasse o "fortalecimento dos vínculos familiares", ou ainda que "a genitora consiga refletir sobre a dinâmica familiar, angarie novos subsídios para respaldar o adolescente". Além disso, PIAs propunham, por exemplo, o "auxílio à genitora" para sua "inserção profissional", "a inserção do nome do genitor nos documentos do adolescente", ou ainda "encaminhamento para o CAT [Centro de Atendimento ao Trabalhador] e CEAT [Centro Especializado de Atendimento ao Trabalhador] para cadastro".

O atendimento desenrolava-se durante os meses seguintes em encontros semanais e individuais com os técnicos; encaminhamentos para serviços públicos de saúde, escolarização e profissionalização; visitas familiares e atividades grupais (como oficinas e grupos de família). Na metade do prazo originalmente estipulado pelo juiz, eram produzidos Relatórios de Acompanhamento bastante sintéticos que tendiam a apresentar os avanços que puderam ser constatados, eclipsando possíveis problemas ou, se incontornáveis, já apontando as ações que haviam sido tomadas para saná-los. Eram documentos de uma ou duas páginas, em que a Situação Familiar usualmente era retratada em não mais do que dois breves parágrafos. O esforço dos técnicos, aqui, era evidenciar um duplo processo de acompanhamento: aquele realizado pela equipe das medidas, e o que o adolescente recebia de sua própria família, como revela esta seção de um dos relatórios transcritos: 
Em visitas realizadas foi possível observar que o adolescente conta com o acompanhamento dos genitores para seu desenvolvimento. A genitora se mostra bem participativa na medida socioeducativa do filho, participa das propostas deste serviço, como reuniões de pais com o intuito de pontuar sobre a responsabilização de cada um na vida do adolescente, grupos de terapia para fortalecer os vínculos familiares, pois a senhora $\mathrm{C}$ se mostra fragilizada diante do comportamento do filho.

Evidenciava-se, sempre que possível, a participação que as famílias vinham apresentando no atendimento e indicadores de suas presenças no núcleo. Nos relatórios isto era exposto, como demonstrado acima, em frases breves, como "participa das propostas deste serviço", cuja justificativa se ancorava na "fragilidade" das famílias em face da situação em que o adolescente se encontrava. Os relatórios eram os documentos enviados ao Departamento de Execuções da Infância e da Juventude (DEIJ) e lidos pelos juízes. Ainda assim, na pasta dos adolescentes mais dois apontamentos que comprovavam a participação eram anexados e poderiam ser acionados, por exemplo, no caso de possíveis audiências: os Registros de Atendimento e os Instrumentais.

Os Instrumentais eram documentos de uma página produzidos, a princípio, para controle interno da Obra Social, que registravam as atividades oferecidas pela Dom Bosco à comunidade como uma exigência dos convênios estabelecidos com os governos municipal e estadual. Neles, as atividades das Terapias eram descritas, por exemplo, como "discussões sobre a família e seu movimento interno", e brevíssimos relatórios enfatizavam que "as famílias foram valorizadas e puderam discutir a importância de pequenas mudanças no cotidiano, para assim conseguirem mais êxito na harmonia familiar".

É evidente que a eloquência das famílias nas reuniões e nos atendimentos individuais era muito importante e influenciava a escrita dos relatórios. Influenciava-os, principalmente, a lançarem mão de expressões-chave fundamentais em seus textos, como participação, respaldo, acompanhamento. Ainda assim, nos documentos que permaneciam nas pastas dos adolescentes, como os Registros de Atendimento, as descrições costumavam ser muito enxutas, apenas apontando os encaminhamentos que a equipe propunha: "a genitora foi convidada a participar do grupo de apoio a família, ou melhor, Terapia Comunitária em [data]", ou ainda, "orientados [o adolescente e seu responsável] sobre o cumprimento. Encaminhado ao CAPS [Centro de Atenção Psicossocial]. Nome na demanda escolar. Processo seletivo no CP [Centro Profissionalizante]. Terapia em 03.12 para [nome da mãe]". 
Nesses documentos, enfim, os enunciados das famílias sofriam uma transubstanciação: as falas das mães nos atendimentos e nas Terapias transformavam-se em registros da presença das genitoras no núcleo. Pelas brechas das informações perdidas (Strathern 1991), novos tipos de informações iam sendo criadas nos papéis.

Finalmente, eram anexadas nas pastas e, no momento oportuno, nos próprios relatórios que seriam enviados aos juízes, as Declarações de Comparecimento, assinadas e carimbadas pelos técnicos que conduziam esses encontros, comprovando a presença dos responsáveis. Receber um carimbo em uma declaração, assinar a lista de presença em cada uma das reuniões, ter a garantia da menção nos Registros de Atendimento construíam, aos poucos, os índices do processo ressocializador. A mobilização desses documentos tornava os relatórios mais confiáveis, atribuindo às evidências empíricas um formato legal (Latour 2010).

E, assim, ao final dos meses estipulados inicialmente como prazo para a medida socioeducativa, os técnicos se encarregavam de elaborar um último documento: a Sugestão de Encerramento. Nele, para garantir que o processo ressocializador fosse visível, acionavam índices que julgavam ser valorizados por cada juiz. Respaldo, encaminhamentos, participação efetiva, apoio, presença, motivação eram algumas dessas expressões que transportavam para outra escala aquilo que os técnicos puderam ouvir e observar ao longo dos meses no núcleo, como se vê no relatório conclusivo de R:

Sra. [nome da mãe] é quem respalda a adolescente durante sua medida socioeducativa, ela a acompanhou desde o início tanto nos encaminhamentos referentes à sua documentação, matrícula escolar, saúde e participação efetiva em grupo de apoio e orientação familiar e atendimento individual [...] A genitora fez parte dos seguintes grupos de família sendo estes: discussão sobre orientação sexual, familiar e adolescência, homenagem ao dia da mulher e de responsabilização quanto à medida socioeducativa. [...] Percebemos que possui bastante apoio não somente da genitora como também de seu padrasto, possuindo assim, um importante respaldo familiar para enfrentamento das dificuldades.

Em nenhum momento se descrevia nesses documentos o que significavam expressões como participação efetiva. Eram termos que, em si mesmos, carregavam certa eficácia, ao menos potencial. O juiz não precisava saber de que modo os pais demonstraram a sua presença no núcleo e, nesse sentido, eram dependentes das informações fornecidas pela equipe técnica. Embora o encerramento da medida dependesse invariavelmente de uma decisão judicial, eram os relatórios técnicos, através dessas expressões muito sintéticas, que instrumentalizavam a possibilidade da sentença. $\mathrm{O}$ 
que o técnico podia fazer era relatar, por exemplo, que a "genitora foi motivada e participou do Grupo de Orientação Familiar no intuito de fortalecer as relações familiares e da Terapia Comunitária que acontece uma vez por mês neste serviço".

Freire (2015), ao fazer etnografia das demandas e dos processos de requalificação civil de pessoas transexuais, argumenta que os documentos construídos pelos operadores do direito, depois de lançarem mão inicialmente de considerações de cunho moral e apelos emocionais, pautavam-se em modelos, apagamentos e homogeneizações. A estratégia técnica de legitimação das demandas operava por um quase completo apagamento de singularidades e trajetórias dos indivíduos. Os documentos produzidos na Dom Bosco, como vimos, também deixavam muito do que as famílias diziam em "pontos cegos" (Strathern 1991; Morawska Vianna 2014). A partir da perspectiva dos técnicos, ser ponte significava ter a capacidade de transformar em frases como "o adolescente está motivado e encarando sua vida com consciência e responsabilidade e está tomando decisões, tendo o apoio familiar" todo o atendimento construído, ao longo dos meses, com os meninos e suas famílias. No entanto, insistindo uma vez mais, esses apagamentos não dispensavam as famílias de a todo o momento falarem de si e falarem dos seus.

\section{Considerações finais}

Através dos dados de campo coletados em dois espaços distintos e que diferiam em natureza, procurei evidenciar o deslocamento enunciativo colocado em movimento pelos técnicos que transformava a voz das famílias em vozes sobre as famílias. E, mais do que isso, que provocava uma mudança transubstancial dessas vozes em papéis juridicamente eficazes. Não havia, à época do trabalho de campo, esforços transcritivos. Havia avaliações técnicas que ofereciam aos juízes espécies de sentenças construídas no núcleo, principalmente a partir da noção de presença das famílias.

A questão que conduziu este artigo poderia ser apresentada como a seguinte: que tipo de efeitos os saberes construídos em reuniões como as Terapias Comunitárias liberavam, e ainda de que maneiras esses efeitos atingiam conjuntamente os adolescentes atendidos pelo núcleo e suas famílias? Antes de limitar minha análise àquilo que escapa aos documentos, procurei apresentar o modo positivo e produtivo (Foucault 2015) em que o silenciamento das famílias nos papéis era operacionalizado pelos técnicos que as acompanhavam e as avaliavam no núcleo. Mesmo que não levassem 
em conta o que era dito nos grupos, era preciso, para que os atendimentos fossem construídos, fazer as famílias falarem. Era preciso que a sua participação e a sua presença fossem passíveis de comprovação.

Procurei descrever os argumentos levantados pelos técnicos para arrastarem as famílias, junto com os adolescentes, para uma série de intervenções: a família era a todo momento entendida como a causa da delinquência e, ao mesmo tempo, como a única capaz de ressocializar os adolescentes. Ela também precisava ser inserida em uma lógica de descrição e normatização (Foucault 2006). De modo semelhante ao descrito por Deleuze (1985), os técnicos (assim como grande parte dos acadêmicos, juristas e militantes dedicados ao tema) pendulavam entre interpretações da família ora como causa, ora como remédio da delinquência; como criadora do desajuste social e como redentora; como o lugar de onde o adolescente precisa ser resgatado e a única verdadeiramente capaz de resgatá-lo. Os profissionais do núcleo de MSE-MA acionavam o protagonismo das famílias através de estratégias constantes de silenciamentos e explicitações.

A família estruturada e participativa era revelada como a verdadeira responsável pelo processo ressocializador. Nos casos em que o adolescente não contava com o respaldo familiar, a iniciativa dele próprio precisaria ser capaz de, com o apoio de um Estado provedor de serviços públicos, superar a defasagem inicial e irrecuperável. Nas duas situações, no entanto, era a família a protagonista do sistema socioeducativo, em um processo que ressoa na "complementaridade assimétrica", descrita por Vianna (2002:296), entre família e aparelho administrativo na gestão de populações consideradas perigosas.

O poder que atravessava os técnicos, trazido pelos saberes que carregavam sobre cada medida em particular, se manifestava no jogo do que era revelado aos juízes pela escrita e o que permanecia reservado à equipe. Quando esses saberes encontravam os juízes, seus efeitos se tornavam incertos e não havia garantias de que as suas definições e os seus diagnósticos coincidiriam com o que os juízes esperavam de cada atendimento. Ainda assim, o saber produzido pela equipe não pode ser negligenciado. Do ponto de vista dos técnicos, as dúvidas sobre aquilo que o juiz suporia adequado para cada caso caminhavam lado a lado com a certeza de que os saberes produzidos pela equipe eram os mais legítimos para auxiliarem o Poder Judiciário em sua decisão. Todas as atividades desenvolvidas durante os meses de LA e toda a atenção da equipe aos índices que consideravam necessários e suficientes para que uma medida socioeducativa fosse considerada adequada eram saberes exclusivamente do núcleo. 
Embora informados pelo Judiciário através das diretrizes e legislações, a natureza do atendimento socioeducativo não é jurídica e, portanto, não podia ser acessada pelo juiz sem o auxílio dos técnicos. Somente esses funcionários eram capazes de atuar como pontes entre essa população específica - suas falas e suas ações - e o que se deveria escrever. E exclusivamente através desse movimento é que os efeitos jurídicos poderiam ser sentidos na vida dos meninos e de suas famílias.

Recebido em 19 de julho de 2016

Aprovado em 03 de abril de 2017

Sara Regina Munhoz é doutoranda do Programa de Pós-Graduação em Antropologia Social da Universidade Federal de São Carlos, São Carlos/SP, Brasil. E-mail: <sararmunhoz@gmail.com>

\section{Notas}

1 O artigo apresenta reflexões e desdobramentos a partir de minha dissertação de mestrado (Munhoz 2013a), financiada pela Fapesp. Agradeço à Catarina Morawska Vianna, ao Jorge Mattar Villela e aos pareceristas anônimos pelas valiosas leituras e sugestões ao texto.

2 Sobre as notações: itálico na primeira vez em que cada um desses termos for apresentado. Para não sobrecarregar o texto, nas aparições subsequentes, utilizarei a grafia normal, a não ser nos casos em que julgue necessário lembrar o leitor de que a minha escrita reflete expressões ouvidas ou lidas em campo. O trabalho de campo foi realizado em 2012, por este motivo optei por manter os tempos verbais no pretérito.

3 Embora o termo seja majoritariamente acionado no masculino, há meninas atendidas no núcleo. Enquanto estive em campo, a proporção era aproximadamente a de 110 meninos para menos de 10 meninas. Sobre as versões femininas a respeito do cumprimento da MSE-MA, conferir Malvasi (2012:168-180).

4 De acordo com Barbosa, Cruz e Vidal (2012:192), profissionais com experiência nas MSE-MA na cidade de São Carlos-SP, as famílias são grupos sociais muito abrangentes compostos de indivíduos que se relacionam cotidianamente e "estão vinculados por laços sanguíneos, de afetividade e outras emoções". Além da definição constitucional de família (Brasil, 1998, art. 226º), ressaltam "novos arranjos familiares" nos quais pessoas convivem em "interdependência afetiva, como nos casos de grupos de irmãos, de avós e netos, caso de uniões homoafetivas, entre outros". 
5 A institucionalização dos adolescentes das MSE-MA encontra ressonância nas "formas de administração da vida" das populações de rua descritas por Martinez et al. (2014): a multiplicação da assistência coexistindo com políticas repressivas constantes. Um tipo de gestão específica que combina intervenções para "fazer viver" e "deixar morrer" (Foucault 2005).

6 Trata-se de um documento entregue às famílias responsáveis pelos adolescentes ao término da audiência em que a MSE-MA é estipulada. Nele se descreve brevemente como a medida deverá ser aplicada e as exigências do juiz. Através do Termo de Entrega, o adolescente e seus responsáveis também são advertidos sobre a possível consequência de um descumprimento da medida: internação-sanção em uma unidade da Fundação CASA por até 90 dias.

7 O nome do adolescente foi substituído por uma consoante aleatória, assim como os outros nomes apresentados neste texto.

8 Sobre os modos como presos e seus familiares entendem o "sofrimento", cf. Feltran (2011a), Biondi (2010), Marques (2014), Ferraz de Lima (2015).

9 Estive presente em quatro reuniões. Em todas elas, o público não superou 15 mulheres. Apenas uma vez presenciei a participação de um pai, e um dos adolescentes atendidos também esteve em um dos encontros, acompanhando sua avó. Além das mães e avós, algumas companheiras (namoradas ou esposas) dos meninos frequentam a Terapia. Quase sempre havia crianças no grupo, levadas por algumas das participantes.

10 O Sistema Nacional de Atendimento Socioeducativo (Sinase) é um documento instaurado a partir da Lei no 12.594 de 2012 que regulamenta a execução das medidas destinadas a adolescentes que pratiquem atos infracionais.

11 Vianna (2005:52) demonstra como a eficácia administrativa em encontrar soluções viáveis para casos jurídicos envolvendo conflitos familiares exige não apenas o "saber fazer falar, mas também seu contrário: não deixar registrado".

12 A distinção entre metas e ações é descrita no Sinase. As metas são os objetivos mais gerais e fixos a serem alcançados ao longo da medida. Ações são as atividades que podem ser realizadas para que essas metas sejam cumpridas. No trabalho cotidiano dos técnicos, no entanto, definir metas e ações sempre era uma atividade que implicava uma série de incertezas (Munhoz 2013b).

13 Além do campo Família, o Contrato de Compromisso apresenta ações para as áreas de Documentação Pessoal, Educação, Profissionalização, Trabalho e Saúde. 
ALTOÉ, S. 1993. De "menor" a presidiário: trajetória inevitável. Rio de Janeiro: Ed. Universitária Santa Úrsula.

BARBOSA, Jacqueline Pereira; CRUZ, Marileide Gonçalvez \& VIDAL, Renata Moura da Silva. 2012. "Práticas no Atendimento Integral às Famílias Acompanhadas pelo Programa de Medidas Socioeducativas: avanços, desafios e perspectivas". In: G.C.S.M. Marques \& A.F.Dias (orgs.), Olhares compartilhados: uma história sobre as medidas socioeducativas em meio aberto no município de São Carlos. São Carlos: Editora Riani Costa. pp. 191-203.

BIONDI, Karina. 2010. Junto e misturado: uma etnografia do PCC. São Paulo: Terceiro Nome.

COSTA, Pedro Henrique Mourthé de Araújo. 2015. Entre os documentos e as retomadas: movimentos da luta pelo território em Brejo dos Crioulos (MG). Dissertação de Mestrado, Universidade Federal de São Carlos.

DELEUZE, Gilles. 1985. "Pensamento mômade". In: S. Marton (org. e rev. téc.) \& M. Nascimento. Nietzsche hoje? Colóquio de Cerisy. Trad. S. Goldberg. São Paulo: Brasiliense. pp. 56-76.

ESTATUTO DA CRIANÇA E DO ADOLESCENTE. 2011. Brasília: Secretaria de Direitos Humanos da Presidência da República e Conselho Nacional dos Direitos da Criança e do Adolescente.

FELTRAN, Gabriel de Santis. 2011a. Fronteiras de tensão: política e violência nas periferias de São Paulo. São Paulo: Editora Unesp.

2011b. "Diário intensivo - a questão do adolescente em conflito com a lei em contexto". Revista Brasileira de Adolescência e Conflitualidade, 2011(4):01-44.
FERRAZ DE LIMA, Jacqueline. 2015. Mulher fiel: etnografia do amor nas prisões do PCC. São Paulo: Alameda. FERREIRA, Letícia Carvalho de Mesquita. 2013. 'AApenas preencher papel': reflexões sobre registros Policiais de Desaparecimento de Pessoa e outros Documentos". Mana. Estudos de Antropologia Social, 19(1):39-68.

FOUCAULT, Michel. 2005. Em defesa da sociedade. São Paulo: Martins Fontes.

. 2006. O poder psiquiátrico. São Paulo: Martins Fontes 2015. A sociedade punitiva. São Paulo: Martins Fontes.

FREIRE, Lucas de Magalhães. 2015. A máquina da cidadania: uma etnografia sobre a requalificação civil de pessoas transexuais. Dissertação de Mestrado, Museu Nacional.

GREGORI, Maria Filomena. 2000. Viração: experiências de meninos nas ruas. São Paulo: Companhia das Letras.

HARAWAY, Donna. 2009. "Manifesto ciborgue". In: T. Tadeu (org.), Antropologia do ciborgue: as vertigens do pós-humano. Belo Horizonte: Autêntica Editora. pp: 33-118.

HULL, Matthew. 2012. "Documents and bureaucracy". Annual Review of Anthropology, 41:251-267.

KAFKA, Franz. 2005. O processo. São Paulo: Companhia das Letras.

LATOUR, Bruno. 2010. Making the law. An ethnography of the conseil d'État. Cambridge: Polity Press.

LEWANDOWSKI, Andressa. 2014. O direito em última instância: uma etnografia do Superior Tribunal Federal. Tese de Doutorado, Universidade de Brasília. 
MALVASI, Paulo. A. 2012. Interfaces da vida loka: um estudo sobre jovens, tráfico de drogas e violência em São Paulo. Tese de Doutorado, Universidade de São Paulo.

MARQUES, Adalton. 2014. Crime e proceder. Um experimento antropológico. São Paulo: Alameda.

MARTINEZ, Mariana M.; PEREIRA, Luiz F. de P.; BARBOSA, Aline R.; OLIVEIRA, Luciano M. F. \& PAZZINI, Domila P. 2014. "A produção e a gestão da população de rua: o caso de Luciene". Dilemas: Revista de Estudos de Conflito e Controle Social, 7(4):741-767.

MIRAGLIA, Paula. 2005. "Aprendendo a lição: uma Etnografia das Varas Especiais da Infância e da Juventude". Novos Estudos Cebrap, 72:79-98.

. 2007. Cosmologias da violência: entre a regra e a exceção. Uma etnografia da desigualdade em São Paulo. Tese de Doutorado, Universidade de São Paulo.

MOL, Annemarie. 2002. The body multiple. Durhan/ London: Duke University Press.

MORAWSKA VIANNA, Catarina. 2014. Nos enleios da tarrafa: etnografia de uma relação transnacional entre ONGs. São Carlos: EDUFSCar.

MUNHOZ, S.R. 2013a. A construção do atendimento em um núcleo de medidas socioeducativas em meio aberto. Dissertação de Mestrado, Universidade Federal de São Carlos. . 2013b. "A elaboração dos documentos na medida". R@U: Revista de Antropologia da UFSCar, 5(2):70-81. . 2015. "O governo dos adolescentes assistidos. A liberdade tutelada oferecida nas medidas socioeducativas em meio aberto". Teoria \& Sociedade, 22(1):134-156.
NERI, Natacha. 2009. "Tirando a cadeia dimenor": a experiência da internação e as narrativas de jovens em conflito com a lei no Rio de Janeiro. Dissertação de Mestrado, Universidade Federal do Rio de Janeiro.

. 2011. "O 'convívio' em uma 'cadeia dimenor': um olhar sobre as relações entre adolescentes internados". R@U,3(1):268-292.

NOGUEIRA DE LIMA, Cauê. 2010. O fim da FEBEM: novas aerspectivas para o atendimento socioeducativo no estado de São Paulo. Dissertação de Mestrado, Universidade de São Paulo.

PAULA, Liana de. 2004. As famílias e as medidas socioeducativas: a inserção da família na socioeducação dos adolescentes autores de ato infracional. Dissertação de Mestrado, Universidade de São Paulo.

. 2011. Liberdade assistida: punição e cidadania na cidade de São Paulo. Tese de Doutorado, Universidade de São Paulo.

REED, Adam. 2006. "Documents unfolding". In: A. Riles (org.), Documents. Artifacts of modern knowledge. Ann Arbor: University of Michigan Press. pp. 158-177.

RILES, Annelise. 2001. The network inside out. Ann Arbor: University of Michigan Press.

RIZZINI, Irene. 2002. "The child-saving movement in Brazil: ideology in the late nineteenth and early twentieth centuries". In: Tobias Hecht (ed.), Minor omissions. Children in Latin American history and society. Madison: University of Wisconsin Press. pp. 165-180.

. 2009. "População infantil e juvenil: direitos humanos, pobreza e desigualdades". In: S. M. Freire (org.), Direitos humanos e questão social na América Latina. Rio de Janeiro: Gramma. pp. 81-88. 
SANTOS, Alessandra Regina dos. 2014. Neste solo em que vós estais, lembrai-vos que é de morrer. Uma etnografia das práticas de caminhar, conhecer e mapear entre os habitantes de Pedro Cubas, um remanescente de quilombo do Vale do Ribeira-SP. Dissertação de Mestrado, Universidade Federal de São Carlos.

SISTEMA NACIONAL DE ATENDIMENTO SOCIOEDUCATIVO (Sinase). Portal da Secretaria de Direitos Humanos. Disponível em: http:// www.sdh.gov.br/clientes/ sedh/sedh/ spdca/sinase. Acesso em 25/05/2016.

SHILITTLER, Maria Carolina. 2011. No crime e na medida. Uma etnografia do Programa de Medidas Socioeducativas em Meio Aberto do Salesianos de São Carlos. Dissertação de Mestrado, Universidade Federal de São Carlos.

STRATHERN, Marilyn. 1991. Partial connections. Walnut Creek, CA: Altamira Press - Rowman \& Littlefield Publishers

VARGAS, Joana Domingues \& MARINHO, Frederico Couto. 2008. "O Programa Liberdade Assistida em Belo Horizonte". Educação e Realidade, 33(2):147-162.
VIANNA, Adriana de R. B. 2002. "Quem deve guardar as crianças: dimensões tutelares da gestão contemporânea da infância". In: Antonio Carlos de Souza Lima (org.), Gestar e gerir: estudos para uma antropologia da administração pública no Brasil. Rio de Janeiro: Relume Dumará. pp. 271-312.

. 2005. "Direitos, moralidades e desigualdades: considerações a partir de processos de guardas de crianças". In: Roberto Kant de Lima (org.), Antropologia e direitos humanos 3 . Niterói: EdUFF. pp. 13-67.

VILLELA, Jorge Mattar. 2011. Ordem pública e segurança individual: política e polícia no Sertão de Pernambuco. São Carlos: EDUFCar.

VOLPI, Mário (org.). 2011. Adolescentes privados de liberdade. A normativa nacional e internacional e reflexões acerca da responsabilidade penal. São Paulo: Cortez.

WAGNER, Roy. 2010. A invenção da cultura. São Paulo: Cosac \& Naify. 
A VOZ DAS FAMÍLIAS E AS

VOZES SOBRE AS FAMÍLIAS

EM UM NÚCLEO DE MEDIDAS

SOCIOEDUCATIVAS EM MEIO

ABERTO

\section{Resumo}

O artigo expõe etnograficamente os modos como a equipe técnica de um núcleo de medidas socioeducativas em meio aberto protagoniza as famílias na construção dos atendimentos a adolescentes autores de práticas infracionais. A partir de dois conjuntos de materiais descrevo como as famílias são convocadas a falar de si e, concomitantemente, são inserias em uma série de documentos elaborados pela equipe. Sem essa dupla presença das famílias no núcleo - nos encontros organizados pelos técnicos e nos papéis produzidos por eles - os atendimentos aos adolescentes não podem ser construídos satisfatoriamente. Apresento, portanto, um deslocamento enunciativo com alcances muito concretos: manejar satisfatoriamente a presença das famílias implicará diretamente nas possibilidades de sucesso da medida socioeducativa.

Palavras-chave Medidas socioeducativas, Liberdade assistida, Atendimento, Família, Documentos.
THE VOICE OF FAMILIES AND

VOICES ABOUT THE FAMILY IN A CENTRE FOR SOCIO-EDUCATIONAL MEASURES IN AN OPEN ENVIRONMENT

\section{Abstract}

This article provides an ethnography of how a technical team in a centre for socio-educative measures in an open environment focuses on the family when framing the assistance of adolescents who have committed crimes. Analysing two sets of ethnographic data, I describe how families are called upon to speak of themselves and, concomitantly, how they are inserted in a series of documents elaborated by the team. Without this dual presence of the family in the centres in meetings organized by experts and in the documents that they produce - adolescents could not be properly assisted. I thus describe an enunciative displacement with a concrete scope: adequate management of the presence of the families directly affects the outcome of the socio-educational measures.

Key words: Socio-educational Measures, Probation period, Assistance, Family, Documents. 
LA VOZ DE LAS FAMILIAS Y LAS VOCES SOBRE LAS FAMILIAS EN UN NÚCLEO DE MEDIDAS SOCIOEDUCATIVAS EN MEDIO ABIERTO

\section{Resumen}

El artículo expone, etnográficamente, los modos como el equipo técnico de un núcleo de medidas socioeducativas en medio abierto hace a las familias protagonistas, en el momento de construcción de los atendimientos a adolescentes autores de prácticas infractoras. Con el uso de dos conjuntos de materiales, describo como son convocadas las familias para hablar de sí mismas y, concomitantemente, como estas mismas son inseridas en una serie de documentos elaborados por el equipo. Sin esas dos presencias de las familias en el núcleo - en los encuentros organizados por los técnicos y en los papeles por ellos producidos - los atendimientos a los adolescentes no pueden ser construidos satisfactoriamente. Presento, por lo tanto, un desplazamiento enunciativo con alcances muy concretos: manejar satisfactoriamente la presencia de las familias, implicará directamente en las posibilidades de éxito de la medida socioeducativa.

Palabras clave: Medidas socioeducativas, Libertad asistida, Atendimiento, Familia, Documentos. 